\title{
Interview Prof. Frank Piller, RWTH Aachen
}

\section{Interview Question}

Nizar Abdelkafi emphasizes that open school becomes a new business model that needs to be understood in much more detail. What are from your perspective the key drivers and barriers for open innovation in higher education?

\section{Author: Prof. Frank Piller, RWTH Aachen}

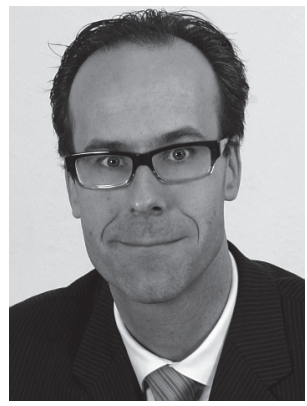

Well, in my opinion the adoption of open innovation methods in a higher education setting faces similar problems like in a corporate setting, and has similar opportunities. Starting with the latter, open innovation enables university administrators to get input from unobvious others for process innovation in an efficient way. "Unobvious" others may include the first-grade student with a great idea for an education app, or the retired professor from India submitting an idea how to conduct physical experiments with large efficiency at low cost. At RWTH Aachen University, for example, we made very good experiences with a broad idea contest for starting students, cocreating with them innovative services to improve the first three months at a large university like RWTH.

At the same time, open innovation provides new opportunities for technology transfer. Responding on Request for Proposals (RFP) posted on OI platforms like NineSigma or InnoCentive can become a very efficient way for university research to reuse (and monetize) existing technical knowledge another time, and to find partners for future funding in research. In a project conducted for the German National Academy of Sciences ("DFG"), we identified a large motivation of both scientists to participate in these contests, and of companies to utilize (in-license or acquire) academic knowledge identified by a RFP.

But, similar to a corporate setting, people have to accept that outside people, often from different fields, are as smart as they are - or even smarter. We know from our research that 'not invented here' also is a phenomenon present in the academic context, and a large barrier to open innovation. Our higher education system still is too disciplinary and provides to little incentives for students and professors to look 'out of their box'.

At the same time, university administrators in general have little knowledge or practice in setting up a structured innovation process. But without an established innovation process, implementing open innovation and co-creation faces large problems - similar to the corporate context! So before focusing on open innovation in higher education, perhaps we first have to do our homework and establish a conventional good innovation process.

Frank Piller is Professor of Technology and Innovationmanagement at the RWTH Aachen University and co-director of the MIT Smart Customization Group at the Massachusetts Institute of Technology, USA. 